UJBM, Vol. 3, No. 1, January - June 2004, pp 59-65 ISSN 0975-3311 | https://doi.org/10.12725/ujbm.4.7

\title{
ROLE OF TECHNOLOGY IN ACCOUNTING, AUDITING AND TAXATION
}

\author{
Suchint Maimudar*
}

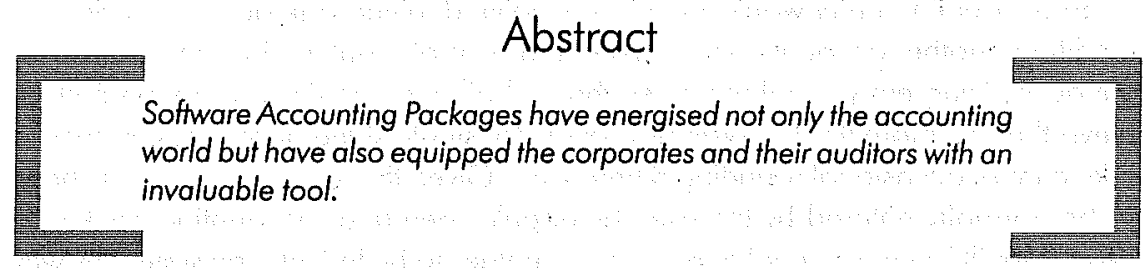

For years, accounting was regarded as being a continuous and tedious exercise, involving long hours of book-keeping and balancing of ledgers and trial balances. This translated in corporate results being declared upto six months after the close of the financial year. Further, not so long ago, book-keeping was entirely manual and it is only recently that the Indian tax law enables accountants to maintain books and the Companies Act enables one to maintain records such as minutes in soft copy form.

Recent developments in software and technology have gone a long way in making the accountants' job far easier in terms of book keeping, enabling them to focus on financial analysis and thus adding significant value in areas such as identifying cost drivers, profitable product lines and sources of financing. Valuable time,

* Finch Software India Pvt Ltd. Bangalore 
which hitherto was spent in the routine tasks of maintaining and tallying books of accounts, can now be put to more profitable use. In the process, the accountant's stature has grown over the years, from being a bean counter to turning into a management accountant and thereafter evolving into a financial decision maker.

Accounting packages come on various platforms, most of them capable of running on Windows. The functionality of accounting packages vary from those that merely provide basic book-keeping to systems which provide analytical cost and financial reports (such as profit/loss by transaction, effect of foreign exchange on profitability, movement and position reports, graphical representation of financial parameters such as break even point) and still others that enable users to create their own reports by extracting various pieces of unrelated data and piecing them together into more meaningful information (for instance, correlating returns on investment in various financial instruments with geographical areas of investment).

At the core, the basic function of the accounting software is to account for debits and credits and automatically post the same to the general ledger thereby leading to the generation of a trial balance at any point of time. How this is done depends on the flexibility the package offers. For instance, most international accounting packages use account number codes, which identify each account. The creation of an accounting entry would therefore involve debiting one account code and crediting another account code. Typically, a control is put in place to ensure that the accounting entry is balanced, so that unbalanced entries are not permitted. Nevertheless, more flexible systems provide for single sided accounting entries to take care of occasional rounding differences. Given that accounting entries have to be normally entered by the user, by popular demand, accounting packages have in-built loaders to enable accounting entries to be fed into the system by way of Excel files or text files (which can be opened in Ultra Edit mode). These files have to be created in a prescribed format (specific to each system) and each element in the data file may have to be separated by way of a semi colon or space, so that the system can identify each element and place it in the right field. SWIFT compliant systems enable messages to be decoded into accounting entries.

For accounting packages that are built around specific ind ustries such as automotive, financial institutions, oil and gas or telecom, the screens are customized to enable ease of data entry and the accounting entries are then created by the system based on the data elements entered in the screen. For instance, an accounting entry can be created for the purchase of a share by a purchaser (Debit investments; credit payable/bank) by entering the security identifier, the date of purchase, the date of setllement, the identification of the purchaser, the quantity and price of the transaction and the financial institution through which the transaction will be settled. 
Equally important is the ability of a financial package to have extensive flexibility, while providing for data manipulation possibilities without compromising on security. It is understood that financial information should be available to users on a need to know basis and so financial systems ordinarily are equipped with high security modules. These define access control on the entities whose accounts are maintained on the system, rights on screens that the user can view or edit and reports which the user is authorized to generate. For example, a maker-checker control will ensure that a single user cannot account a transaction all by himself - if it is created by one user, it has to be validated by another. Flexibility of an accounting package entails the definition by a user of the accounting schema - in short, the controller should be able to create a user-defined accounting chart, in terms of account naming or coding convention without system intervention. Further, a lot of companies maintain confidentiality by encouraging the usage of passwords so that the information stored on a particular computer system cannot be accessed by anybody else in the organization. Another facet to flexibility is the ability of an accounting system to maintain and manipulate several clients on a single system.

Again, it is important to keep in mind that accounts of an entity are almost always migrated on to the accounting platform, rather than created afresh and so it should be possible for account balances and stock or porffolio positions to be brought on to the accounting platform without significant difficulty. Typically, flat files, such as those which can be created and viewed in Ultra Edit or Notepad mode or comma delimited formats are used, whereby data from the legacy system can be extracted and turned around into the desired format for injecting into the new system. Some of the subtle possibilities that accounting systems offer are the ability to reverse transactions rather than deleting or editing entries, the tracking of users who have booked transactions or created or amended parameters in the system so as to maintain an audit trail. More flexible systems also enable users to copy accounts of an entity into a dummy database, so that what-if scenarios can be run on the copied database or the copy can be retained as a backup during year-end closing. Besides, since accounts take up quite a bit of disc storage space and historical books are not all that relevant after a couple of years, accounting systems also provide users the ability to archive or delete prior information, by taking a snapshot of account balances as of the archive date and taking the accounts forward from thereon.

As with input feeds, accounting products normally enable users to generate reports and extract and export information into various interfaces. Standard reports of the system can be extracted as text files and opened in Excel or Acrobat Reader or HTML formals. Ideally, the accounting information is also exported into an Infocentre, so the user can build a strategy around the data warehouse in terms of downstream 
use of the accounting information. It is also possible for the user to pre-set timings of import and export feeds, so that the accounting system can be programmed to auto-account transactions and generate reports to a destination drive or printer.

Increasing regulatory reporting requirements, standardization of accounting treatments and an urgency in making the financials known to stakeholders have also played a role in the evolution of financial accounting platforms. Accounting systems do enable the reconciliation of financials for US GAAP or IFRS in one way or another, though there are few systems that can mirror the books of account on a real time basis using different accounting bases. Further, reporting the summary financials (especially in the case of registered investment companies or open ended investment companies) to NASDAQ has to take place in the prescribed format and accounting systems should have self-contained interfaces to be able to generate the files for stock exchange reporting.

As each country's tax and regulatory laws can be varied and fairly complex, it may not be possible to incorporate all of these laws into the accounting module. Nevertheless, basic tax rate maintenance function is generally present in each accounting system and especially in the area of indirect faxation, where excise, service tax and sales taxes are integrally connected with production and sales, accounting systems are upto speed, so that it is possible to reconcile the actual excise liability with the amount of excise duty paid or treated as paid (i.e. in the form of taxes paid on raw material inputs).

In addition, regulatory reporting, such as investment restrictions, foreign exchange receipts, tracking of foreign withholding taxes versus tax credit available and ratio analysis can also be performed to varying extents by the software. As companies go global and are quoted in several markets around the world, for facilitating the trading of the scrip, it is in effect possible to value an investment in a company at any point in time, just because round the clock, one or the other stock exchange is working. Investors and portfolio managers are therefore increasingly requiring information on valuation to be oblained on a real time basis from the accounting and pricing systems, to identify and leverage arbitrage opportunities. In this context, processing speed of the system remains of the essence and it is essential for the accounting systems to be programmed in a way so as to provide real time information, in the form of screen views, reports and calculations.

Several other facets go into accounting for transactions in a global context. Foreign currencies, interest rates, price movements, all act at the same time in the valuation of a foreign currency fixed income bond. Companies also have to enter into foreign currency forward contracts, interest rate swaps or purchase options to contain price or exchange risks. Whereas in a traditional accounting environment, these 
transactions would be regarded as being? off balance, requiring only a disclosure, the ability of an accounting system to blend traditional accounting with financial management concepts such as the determination of forward exchange rates based on forward interest rates or the valuation of a fixed income instrument based on its yield to maturity would benefit both the accountant as well as the portfolio manager.

Withholding tax returns form part of downstream applications of accounting. As and when taxes are withheld by an entity, it has to make payments of withholding taxes and furnish appropriate returns to the Revenue authorities. Typically, all the information concerning receipts, payments, incomes and expenses resides in the accounting system and it is therefore possible to retrieve and export the tax related information directly from the accounting system to the Revenue authorities. As it is, the Revenue authorities in India are accepting returns in electronic media and making payments of refunds by electronic clearing. It depends on the complexity of tax law, though the extraction of reports from the accounting system by way of a Report Builder does make it possible for an architecture to be constructed around the accounting system which will enable a macro-level calculation and detailed reporting of taxes.

India is one of the countries to have evolved and dealt with fairly complex tax legislation. State of the art concepts such as transfer pricing, advance rulings and transfer of business already form part of the Indian tax code. Besides, the elaborate judicial structure of income tax and appellate authorities has given rise to case laws on several points of fact and law. It is well nigh impossible to maintain an updated library of case laws and statutes and more importantly retrieve information pertaining to these laws or statutes at random. Add to this the fact that at times, exchange control or company law has a bearing on tax law and one is faced with a plethora of precedents and pronouncements, so much so it is like searching for a needle in a haystack. It is here that CD-Rom and web-based libraries have come to the rescue of tax accountants. These libraries, maintained in electronic form, facilitate the search of case laws based on Google- search engine like technology. Of course, the Revenue authorities have also kept up with this change albeit slowly, in the process ensuring that more cases can be speedily resolved based on documented precedents and even if cases were to be elevated for want of precedents or a review of an earlier case, finer points of law, fact and legislative intent are debated upon instead of adjournments for going back for research.

The recent introduction of transfer pricing legislation has necessitated a great deal of fieldwork on comparable uncontrolled transactions and determination of arm's length price. The rapidity with which this legislation could be complied with without invoking safe harbour provisions was possible due to the spawning of several databases which provided corporate financials across several sectors. This made 
it possible for tax professionals to rely on these databases and reach conclusions on whether their clients had to revisit their transfer price vis-a-vis their overseas related enterprises.

E-filing of returns, the proliferation of a permanent account number, harmonization of technologies of banks and corporates and electronic banking has made it possible for an honest taxpayer to simplify the taxation information gathering considerably. Here, we are not talking about populating Excel-based spreadsheets, which is simple enough, but instead using relational databases to prevent duplication of work. For example, transfer of funds from one account to another over the Net (ebanking, as it is popularly referred to) constitutes an electronically documented transaction, something that can be used for book keeping purposes by the transacting parties as well as the depository bank and can be readily furnished to the Revenue authorities if so desired. The convergence of mobile and web-based technologies, coupled with the fantastic reduction in the size and cost of memory has led to the evolution of hand held devices such as the Blackberry or the Pocket PC, thereby bridging the gap between front office (transacting) and back office (record keeping) activities.

The winds of technological change have also blown in the area of auditing, where auditors increasingly rely not only on procedures such as vouching, involving the physical verification of documentation evidencing transactions, but also the security and data manipulation possibilities of the computer system on which the accounts of an enterprise are maintained. Auditing around the computer (basing the audit on documentation alone, bypassing the computer) has given way to auditing through the computer, whereby the accounts of a concern are not only verified from an authenticity point of view but in addition, cash flows and account movements are examined, so that the accounts aid the understanding of the business intent and the propriety of the management.

The different business cycles of an enterprise such as purchaso, sales, fixed assets and payroll are tested on a rotational basis by testing a transaction from its inception till the final payments are made. Automated accounts also facilitate generation of variances between the budgeted amounts and the actual amounts recorded in the financial statements. If there is an abnormal variance the management has to provide explanation for the same which in turn will enable the auditor to corroborate changes that have taken place in the client's business. The sheer size of the companies today requires the auditor to carry out audit of transactions till an interim period. Automation of accounts enables the auditor to carry out a roll forward transaction analysis when the audit is undertaken at the close of the relevant financial year. This avoids duplication of work. 
In conclusion, technology (typically more software than hardware), has transformed the staid and orthodox world of accounting and taxation, making it more exciting, analytical and creative and positioning it as a value added function in an enterprise. Aspiring accountants will be glad to know that technology has taken away the labour element in the finance domain, leaving in its wake challenges and opportunities. 